\title{
Researching Driving Mechanism and Ways of Innovation Development on Rural Tourism
}

\author{
Jinghui Qu \\ School of Management, Liaoning Institute of Science and Technology, Benxi, Liaoning 117004, \\ China
}

Keywords: Rural tourism; Driving mechanism; Transformation; Innovation

\begin{abstract}
Rural tourism is a tour type based on rural community with the unique form of production, life style and pastoral scenery, which is of vital to cope with issues concerning agriculture, countryside and farmers, to bridge the income gap and to promote urban and rural overall plannings. It is essential to improve quality and effect in local tourism industry. Rural tourism in Liaoning province has formed scale and brand effect with abundant resources in recent years, but it is suffering bottleneck due to various factors which limits its economic and social function in need of the support from theoretical study and innovation. This paper puts forward six ways of innovation on rural tourism from the practice of rural tourism in Liaoning province by a theoretical analysis and an empirical method.
\end{abstract}

\section{Introduction}

Rural tourism is the most alternative tourist product within urbanization which is a product of modern urban life and environmental pressure and a result of pursue of a higher quality life. As a comprehensive tourist product making use of agricultural resources, after a organic integration of the primary and tertiary industry, rural tourism improves rural infrastructure construction and achieves the financial collection of the social and economic development in rural area. Moreover, it changes the traditional economic pattern in Chinese countryside, promotes agricultural economic efficiency and improves income of farmers. Rural tourism plays an important role in improving the environment, farmers' quality of life, productivity growth and industrial structure. It becomes a new way to change the development of rural economy and build a new socialist countryside and the socialist harmonious society.

\section{Driving Mechanism of Innovation on Rural Tourism}

The development of rural tourism in China started in 1980s, and it has now entered into a period of scale and transformation. The key to economic transformation is to radically transform the way of development, and make fundamental changes in track, operation situation and driving mechanism, so as to improve the quality and efficiency of economic operation and achieve sustained and healthy economic development. Transformation is a profound change in economic society. It involves the distribution of interests of all social classes and inevitably faces various resistance and obstacles. Therefore, we need a strong force to break the original benefit structure, so as to drive all the parties to cooperate actively, and the transformation can be finished completely. Thus, the economic transformation needs sufficient driving force. The development of rural tourism to the transition period needs innovation and development, and the innovation and development need to have a strong creativity.

\section{Demand-- Promotion of Demands Force Driving Mechanism}

Tourism is no longer just a whistlestop trip but relax. The changes in demand for independent travel without help of travel agencies required innovative tourism activities and product from tourism enterprises. Production is for consumption, and production is consistent with market demand. With the escalation of social changes in final consumption demand, the social production surrounded by consumption demand will change, thus a change of production demand will occur as well. Then through the industrial chain of the input and output link, the whole society production 
process chain is promoted leading to a transformation of mode of economic development. Hence, the demand of consumers will force driving effects on the social production, and the upgrade of tourist demand is exactly the strong driving force for tourism innovation development.

\section{Policy-- Transformation of Institutions Force Driving Mechanism}

The great practice of China's rural reform and development has made a ingenious exploration for the establishment and improvement of China's economic system and market economy system, which achieves a historic leap and accumulates valuable experience.

The change of the society is always accompanied by the change of systems, and the change of systems promotes the change of the society. At present, Chinese economic development is facing new difficulties and challenges, it is urgent for new power to activate the economic development through institutional adjustments, to provide a favorable environment to new development patterns while providing sufficient government policy in order to accelerate the development of replacement process. From traditional agriculture to modern agriculture, new urbanization is driven by institutional change. The innovation and development of rural tourism is an inevitable trend driven by institutional change.

\section{Technology-- Technical Innovation Forces Driving Mechanism}

The progress of science and technology is a powerful motivation to boost economic transformation. Scientific and technological innovation is an important support to drive economic transformation. It is a powerful engine for today's social economic transformation. On the one hand, it can overcome the constraints of some factor supply, alleviate or even eliminate the bottleneck of economic development, and find potential for growth. For another, with the change of the structure of supply factors, various elements of price comparison changes, directly change the production curve of manufacturers, affect their production decisions, so that it is possible that a new mode of production replaces the old mode of production, then promoting the transformation of economic development mode. Therefore, technological innovation is not only a powerful driving force of economic transformation, but a new type of tourism innovation. Tourism virtual network and tourism information platform has emerged, and the development of traveling informationized has become a powerful driving force for the development of rural tourism.

Driving Mechanism of New Concepts-- Concepts Influence and Determine People'S Act.

When the concept of development of the whole society changes fundamentally, it will guide people to consciously change the way of behavior, thus promoting the transformation of the economy and society. First, the new concept of scientific development will influence the formulation and implementation of the comprehensive economic system, national policy, and give full play to the "visible hand" to promote economic restructuring. Second, when most consumers are aware of and accept the new scientific development concepts, they will consciously change the consumption concepts and behaviors, and they will resist products which not accord with scientific development concepts, becoming a powerful social force to promote the transformation of the mode of economic development. For example, influenced by green consuming idea, European consumers consciously resist those non organic food who have to change its business philosophy and actively cater to the consumer's needs.

\section{Ways of innovation on rural tourism}

\section{Innovation of Rural Tourism based on Transformation and Upgrading Upgrading of the industrial pattern}

Agricultural projects should be upgraded from modern agriculture to creative agriculture, leisure agriculture, science and technology agriculture and agricultural tourism with unique feature and new brand. Through upgrading the existing industry and introducing new industries, increasing the compound ability of the park, and ultimately achieving the overall upgrading of the industry, especially the injection of tourism, which can promote the comprehensive development of the tertiary industry in the park.

Upgrading of the urban function

We should give full play to the support and feedback function of tourism to agriculture and the 
radiation and driving role of the city to the suburbs, and establish a long-term mechanism of tourism to drive agriculture and urban rural areas, so as to promote the coordinated development of urban and rural areas.

Upgrading of the time and space

Scenic spots upgrade from the traditional single season four seasons-- scenic area, agricultural seasons, four seasons experience. Tourists can only enjoy themselves in the day and have a rest at night in the past, but now they can stay here and have fun at night as well with abundant activities meeting the needs of leisure tourists.

Upgrading of the recreation

People in modern society place more emphasis on spiritual release, self satisfaction and personal experience. Rural tourism projects should concern these issues relying on water resources, organic agriculture, the development of some of the original health resort experience, modern agriculture and the experience of parent-child play, creating a distinctive and upmarket agricultural leisure complex.

Upgrading of the scenic tour and rest

In the rural tourism project, we should introduce water resources and upgrade the landscape to increase the visual effect. Combining with the agricultural production, we should add some landscape of the earth. At the same time, we should strengthen the internal transformation of the park, set reasonable tourist routes, and enhance the overall image of the project.

\section{Innovation of Rural Tourism based on Recreational Development}

It is difficult to earn money just from agriculture, which needs long-term investment but the output is limited. Neither the local agricultural tourism nor the domestic upmarket agricultural sightseeing project or the national agricultural demonstration base, agriculture projects cannot merely bring suitable economic benefits. As for more economic benefits, I think the rural tourism project should break through the traditional rural leisure projects, jump out of agricultural production into the pastoral way of life, retaining the high-end consumer groups to stay so as to form its soft power, invisible business model and "brand integration strategy".

\section{Innovation of Rural Tourism based on the Construction of Beautiful Countryside}

To carry out land circulation, the implementation of "major tourist project"and construct tourism brand.

To promote the environmental renovations and build "beautiful countryside"and leisure travel in rural area.

To propel the rural reconstruction and "new type of rural community"with the attractive agritainment development of leisure tour.

To construct industrial system and introduce " tourist industry "with the tertiary industry at the head of tourist service.

\section{Innovation of Rural Tourism based on New Model of Urbanization}

Within the new urbanization ,rural tourism development pattern should be the "new urbanization" which caused "new tourism development", "significant tourism development" nurturing "new urbanization", as shown in figure 1.

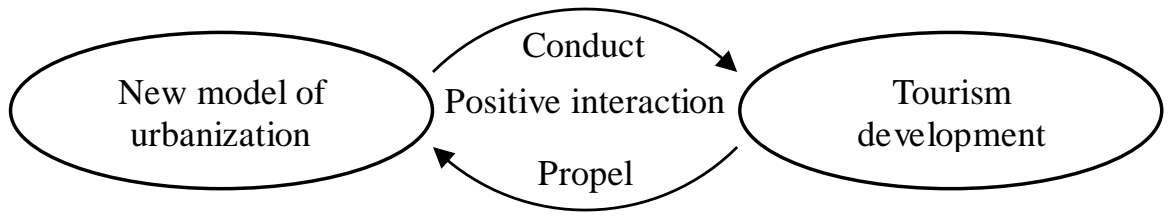

Figure 1. relationship between tourism and new urbanization 


\section{Innovation of Rural Tourism based on technology}

To strengthen the driving force of science and technology, we must establish and improve the incentive mechanism of innovation, activate the vitality of the micro main body, and make them dare to innovate, innovate and innovate successfully, which can be represent in the following 3 aspects:

Setting up a new risk compensation mechanism to reduce the expectation of innovation risk

Creating favorable conditions to make the micro body have the ability to innovate

Creating a market environment conducive to innovation and improve the success rate of innovation

\section{Innovation of Rural Tourism based on Institutions}

To promote financial innovation actively. To explore the new financing mechanism, in order to raise funds for construction projects supporting the innovative financing channels and operation mode; improve the coordinated development of urban and rural financial system innovation, for the coordinated development of urban and rural areas to provide more financial support; to explore the green financial system, provide more financial support to meet the requirements of the scientific outlook on development company.

To propel the reform of the fiscal and tax system. The establishment and improvement of the financial system which is conducive to the transformation of the mode of economic development and the conservation of resources. We should promote the reformation of the budget, optimize the structure of fiscal expenditure and improve the efficiency of the usage of financial funds.

To deepen the reform of household registration, education, medical treatment and employment, and break the institutional barriers of urban and rural gap, and realize the integrated development of urban and rural areas.

To explore the effective mode of rural land circulation, to realize the intensive management of land and promote the development of modern agriculture.

\section{Acknowledgements}

This work is supported by the Social science planning fund project of Liaoning province in 2017 Research on tourism industry of innovation development in Liaoning province. (Project number: L17BJY002)

\section{Reference}

[1]Ding Peiwei. Current situation and selection of ways on China's rural tourism development in the last three decades [J]. Dongyue Tribune,2011(07):114-118.

[2] Ma Liang,Yan Tingyu.Study of innovation system on rural tourism.[J].Chinese Agricultural Science Bulletin,2013 (32).

[3]Zhang Qing.Analysis of the development on rural tourism of Longyan.[J].Journal of Longyan University,2013(03):67-72

[4] Shan Fubin. Analysis of the development on rural tourism of Langfang [J].Journal of Hebei Agricultural Science,2012(01).

[5] Peng L. Individual Choice and Reputation Distribution of Cooperative Behaviors among Heterogeneous Groups. Chaos, Solitons \& Fractals, 2015, 77: 39-46.

[6] Diao Zhibo. Analysis of the development on rural tourism of Heilongjiang province[M].Tourism Education Press,2014(04) 